\title{
Dynamic Analysis of Curved Box Girder Bridges
}

\author{
Dr. Ayad A. Abdul Razzak \\ Assistant Professor \\ Zeena A. Mohammad \\ Assistant Lecturer \\ Mosul University/ Civil Engineering Department
}

\begin{abstract}
A higher order finite strip formulation based on the auxiliary nodal line (A.N.L.) technique for a dynamic analysis of curved box-girder bridges is presented. Newmark's equations of numerical integration have been applied depending on the values of the coefficients $(\beta, \gamma)$, and adopted in the current study with a value equal to $(0.5,0.25)$ of a curved box girder bridge with simple support and exposed to the traffic of the moving vehicles represented by the system of the moving force. Where the dynamic interaction between the vehicle and the bridge is neglected.

The study has also required the application of Newmark's method to find out the dynamic response values represented by (deflections, dynamic amplification factor, Impact factor) to solve the issues related to the bridge loaded by moving vehicles model. Each system is composed of a suspended mass joined with a damper and a spring of stiffness in addition to the unsuspended mass.
\end{abstract}

Keywords: Curved Box Girder Bridges, Dynamic Analysis, Finite Strip.

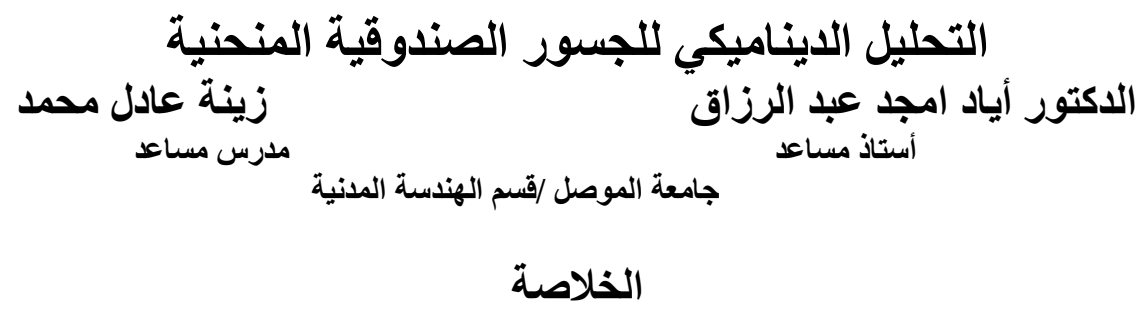

طبقت طريقة الشريحة المحددة ذات النسق العالي مع تقنية الخط العقدي المساعد لإجراء التحليل الايناميكي لجسور صندوقية منحنية. واستخدمت طريقة (نيومارك) للتكامل العددي بالاعتماد على قيم المعاملات ( اعتمدت عليها الاراسة الحالية بقيمة مساوية لـ(0.5 و0.25) لجسر صندوفي منحن بسيط الإسناد المعرضة لمرور لمرور

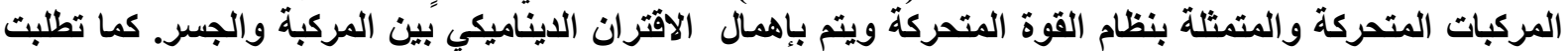

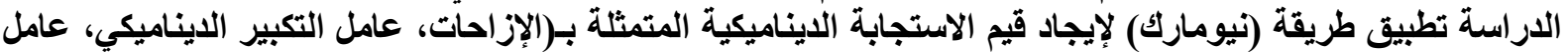

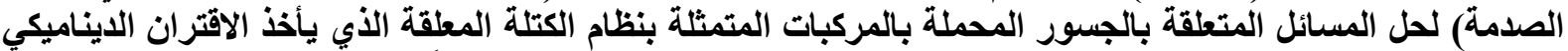
بنظر الاعتبار إذ تتألف كل منظومة من كتلة معلقة مرتبطة بمخمد وبنابض جساءة فضلاً عن الكتلة غير المعلقة.

الكلمات الدالة: الجسور الصندوقية المنحنية، التحليل الديناميكي ، الثريحة المحددة ذات النسق العالي.

Received: 17 - 7 - 2013

Accepted: 7 - 10 - 2013 


\section{Notation}

\begin{tabular}{|c|c|}
\hline A.N.L & Auxiliary Nodal Line. \\
\hline$B$ & Strain matrix. \\
\hline$b$ & Width of strip \\
\hline$C$ & Coefficient matrix for displacement function. \\
\hline$C_{S} C_{P}$ & Damping of tire and Damping of sprung mass respectively. \\
\hline $\mid C_{v}$ & Damping matrix of vehicle. \\
\hline$D$ & Rigidity matrix \\
\hline $\overrightarrow{D A F}$ & Dynamic Amplification Factor. \\
\hline$\ddot{d} m \dot{d} m d_{m}$ & $\begin{array}{l}\text { Verticals displacement, Velocity and Acceleration of sprung mass } \\
\text { respectively. }\end{array}$ \\
\hline$E_{x} E_{\theta} E_{x \theta}$ & Orthotropic material properties. \\
\hline$\{F\},\{F\}^{*-0}$ & Vectors of nodal force and Effective of nodal force respectively. \\
\hline$f^{c p}$ & Interaction at contact point. \\
\hline$\left\{f_{v}\right\},\left\{f_{v}\right\}^{*}$ & Vectors force of vehicle and effective force of vehicle respectively. \\
\hline $\operatorname{Imp}$ & Impact Factor. \\
\hline$[K],[K]^{*},\left[K_{v}\right]$ & Stiffness, Effective stiffness and Stiffness of vehicle matrices \\
\hline$K_{p}, K_{s}$ & Stiffness of tire and Stiffness of sprung mass respectively. \\
\hline$Q$ & External load. \\
\hline$M$ & Mass of vehicle \\
\hline$\left[M_{c}\right],\left[M_{c}\right]^{*}$ & Mass matrix and Effective mass matrix respectively. \\
\hline$m_{p}, m_{s}$ & Mass of tire and Sprung mass respectively. \\
\hline$\left[m_{v}\right],\left[m_{v}\right]^{*}$ & Mass matrix of vehicle and Effective mass matrix of vehicle respectively. \\
\hline$t$ & Time. \\
\hline$T$ & Transformation matrix. \\
\hline$x$ & Transverse coordinate of strip \\
\hline$\alpha$ & Subtended angle of curved bridge. \\
\hline$\beta, \gamma$ & Parameters of Newmark time integration scheme. \\
\hline$\delta_{m}{ }^{c p}, \dot{\delta}_{m}{ }^{c p}, \dot{\delta}^{c p}{ }_{m}$ & $\begin{array}{l}\text { Verticals displacement, Velocity and Acceleration at contact point } \\
\text { respectively. }\end{array}$ \\
\hline$\left\{\delta_{m}\right\},\left\{\dot{\delta}_{m}\right\},\left\{\ddot{\delta}_{m}\right\}$ & Vectors displacement, Velocity and Acceleration of bridge respectively. \\
\hline$\{\varepsilon\},\left\{\sigma_{m}\right\}$ & Strain and Stress vectors respectively. \\
\hline 0 & Poison's ratio. \\
\hline
\end{tabular}

\section{Introduction}

Vibration of bridge structure under the passage of vehicles is an important consideration in the design of bridges. Dynamic response of bridges has assumed added significance with the advent of faster and heavier vehicles and the use of structural forms and materials that permits the bridge to be more slender.

Interaction between the vehicle and the bridge is complex dynamic phenomenon. This complexity results from the large number of different parameters that may affect the dynamic response [1]. 
During the past decades, extensive works have been under taken to study the factors affecting the dynamic response of bridges, Mukherjee and Trikha [2] investigation the influence of span, radius of curvature, span/depth ratio and the speed of moving load have been indicated on the maximum values of dynamic factors for individual girders.

In 1997, Senthilvasan etal. [3] presented a simple procedure for modeling and analyzing the dynamic behavior of curved box girder bridges based on the curved spline finite strip method, investigation the influence of several important parameters such as: (1) The curvature of bridge, (2)mass ratio (mass of vehicle/ mass of the bridge), (3) speed of vehicle, (4) support conditions, etc.

To investigate the dynamic response of box - girder bridge Abdul-Razzak and Mohammad in (2005) [4] study a higher order finite strip with sixth order bending strips combined with third order in-plane displacements functions have been used to obtain the analysis of simply supported box- girder bridges under moving force.

In (2007) Abdul-Razzak and Haido [5] studied the effects of some parameters on the vibration of the plates subjected to dynamic load. The forced vibration analysis by using a higher order finite layer formulation based on the auxiliary nodal surface (A.N.S.) technique for analysis of rectangular plates, by applying the Newmark method for investigating the vibration characteristics and finding the response of the rectangular plates under the action of dynamic loads

In (2008) Abdul-Razzak and Haido [6] investigated the dynamic response of beam under moving vehicles. The bridge is idealized by a rectangular isotropic or orthotropic plate and vehicle is represented by a one-foot dynamic system with the unsprung mass and sprung mass interconnected by a spring and a dashpot. Higher order finite layer method have been used to simulate the dynamic interaction between abridge deck and moving vehicle.

In present study, a refined finite strip method is applied for the force vibration of curved box-girder bridges using higher order conical frustum shell strip. The auxiliary nodal line (A.N.L.) technique has been adopted for both bending and membrane actions. The vehicle has been represented by single moving force with the same velocity as the vehicle.

\section{Formulation of Shell Strip Characteristics: Basic Assumption}

For the general conical shell strip with one auxiliary nodal line, a sixth order displacement function to represent the variation of the normal displacement components $\mathrm{W}$ was used, and a third order displacement function to represent the variation of the membrane displacements $\mathrm{U}$ and $\mathrm{V}$ were used, as follows [7]:

$$
\begin{aligned}
W & =\sum_{m=1}^{n}\left[C_{w}\right]\left\{W_{m}\right\} \sin \frac{m \pi \theta}{\alpha} \\
& =\sum_{m=1}^{n}\left[C_{1}, C_{2}, C_{3}, C_{4}, C_{5}, C_{6}, C_{7}\right]\left\{W_{m}\right\} \sin \frac{m \pi \theta}{\alpha}
\end{aligned}
$$

where:

$$
\begin{aligned}
& C_{1}=1-39 S^{2}+162 S^{3}-276 S^{4}+216 S^{5}-64 S^{6} \\
& C_{2}=x\left(1-8 S+25 S^{2}-38 S^{3}+28 S^{4}-8 S^{5}\right)
\end{aligned}
$$




$$
\begin{aligned}
& C_{3}=48 S^{2}-244 S^{3}+432 S^{4}-384 S^{5}+128 S^{6} \\
& C_{4}=x\left(-8 S+32 S^{2}-40 S^{3}+16 S^{4}\right) \\
& C_{5}=x^{2}\left(2-12 S+26 S^{2}-24 S^{3}+8 S^{4}\right) \\
& C_{6}=-9 S^{2}+62 S^{3}-156 S^{4}+168 S^{5}-64 S^{6} \\
& C_{7}=x\left(S-7 S^{2}+18 S^{3}-20 S^{4}+8 S^{5}\right)
\end{aligned}
$$

in which $S=x / b$

$$
\begin{aligned}
\left\{W_{m}\right\} & =\left[W_{i m}, \theta_{i m}, W_{c m}, \theta_{c m}, \gamma_{c m}, W_{j m}, \theta_{j m}\right]^{T} \\
U & =\sum_{m=1}^{n}\left[C_{U}\right]\left\{U_{m}\right\} \sin \frac{m \pi \theta}{\alpha} \\
& =\sum_{m=1}^{n}\left[C_{1}, C_{2}, C_{3}, C_{4},\right]\left\{U_{m}\right\} \sin \frac{m \pi \theta}{\alpha} \\
V & =\sum_{m=1}^{n}\left[C_{V}\right]\left\{V_{m}\right\} \cos \frac{m \pi \theta}{\alpha} \\
& =\sum_{m=1}^{n}\left[C_{1}, C_{2}, C_{3}, C_{4},\right]\left\{V_{m}\right\} \cos \frac{m \pi \theta}{\alpha}
\end{aligned}
$$

in which $\left[C_{U}\right]=\left[C_{V}\right]$

where:

$$
\begin{aligned}
& C_{1}=1-5 S+8 S^{2}-4 S^{3} \\
& C_{2}=4 S-4 S^{2} \\
& C_{3}=b\left(-2+6 S-4 S^{2}\right) \\
& C_{4}=S-4 S^{2}+4 S^{3}
\end{aligned}
$$

in which $S=x / b$

$$
\begin{aligned}
& \left\{U_{m}\right\}=\left[U_{i m}, U_{c m}, \frac{\partial U}{\partial X}_{c m}, U_{j m}\right]^{T} \\
& \left\{V_{m}\right\}=\left[V_{i m}, V_{c m}, \frac{\partial V}{\partial Y}{ }_{c m}, V_{j m}\right]^{T}
\end{aligned}
$$

\section{Strain}

The equations of strain displacement relations for a conical shell have been derived by Novozhilov [8], and they are found to be most appropriate. 


$$
\left.\left\{\begin{array}{c}
\varepsilon_{x} \\
\varepsilon_{\theta} \\
2 \varepsilon_{x \theta} \\
X_{x} \\
X_{\theta} \\
2 X_{x \theta}
\end{array}\right\}=\left\{\begin{array}{c}
\frac{\partial U}{\partial X} \\
\frac{1}{r} \frac{\partial V}{\partial \theta}+\frac{W \cos \phi+U \sin \phi}{r} \\
\frac{1}{r} \frac{\partial U}{\partial \theta}+\frac{\partial V}{\partial X}-\frac{V \sin \phi}{r} \\
-\frac{\partial^{2} W}{\partial X} \\
-\frac{1}{r^{2}} \frac{\partial^{2} W}{\partial \theta^{2}}+\frac{\cos \phi}{r^{2}} \frac{\partial V}{\partial \theta}-\frac{\sin \phi}{r} \frac{\partial W}{\partial X} \\
2\left(-\frac{1}{r^{2}} \frac{\partial^{2} W}{\partial X \partial \theta}+\frac{\sin \phi}{r^{2}} \frac{\partial W}{\partial \theta}+\frac{\cos \phi}{r} \frac{\partial V}{\partial X}-\frac{\sin \phi \cos \phi}{r^{2}} V\right.
\end{array}\right)\right\}
$$

in simple form:

$$
\left\{\varepsilon_{m}\right\}=\left[B_{m}\right]\left\{\delta_{m}\right\}
$$

Where:

$$
\left\{\delta_{m}\right\}=\left[U_{i m}, V_{i m}, W_{i m}, \theta_{i m}, U_{c m}, V_{c m}, \frac{\partial U}{\partial X}, \frac{\partial V}{\partial Y}, W_{c m}, \theta_{c m}, \gamma_{c m}, U_{j m}, V_{j m}, W_{j m}, \theta_{j m}\right]^{T}
$$

\section{Stresses}

The stresses encountered in the strain energy of shell strip, for the orthogonal anisotropic material, are given by [7]:

$$
\left\{\begin{array}{c}
N_{x} \\
N_{\theta} \\
N_{x \theta} \\
M_{x} \\
M_{\theta} \\
M_{x \theta}
\end{array}\right\}=\left\{\begin{array}{cccccc}
K_{x} & K_{2} & 0 & 0 & 0 & 0 \\
K_{2} & K_{\theta} & 0 & 0 & 0 & 0 \\
0 & 0 & K_{x \theta} & 0 & 0 & 0 \\
0 & 0 & 0 & D_{x} & D_{2} & 0 \\
0 & 0 & 0 & D_{2} & D_{\theta} & 0 \\
0 & 0 & 0 & 0 & 0 & D_{x \theta}
\end{array}\right\}\left\{\begin{array}{c}
\varepsilon_{x} \\
\varepsilon_{\theta} \\
2 \varepsilon_{x \theta} \\
X_{x} \\
X_{\theta} \\
2 X_{x \theta}
\end{array}\right\}
$$

in which:

$$
\begin{aligned}
& K_{x}=\frac{E_{x} h}{1-v_{x} v_{\theta}} \quad 6 K_{x \theta}=G_{x \theta} \cdot h \quad 6 K_{2}=v_{\theta} K_{x} \quad 6 K_{\theta}=\frac{E_{\theta} h}{1-v_{x} v_{\theta}} \\
& D_{\theta}=\frac{E_{\theta} h^{3}}{12\left(1-v_{x} v_{\theta}\right)} \cdot D_{x \theta}=\frac{G_{x \theta} \cdot h^{3}}{12} \cdot D_{2}=v_{\theta} D_{x} \cdot \quad D_{x}=\frac{E_{x} h^{3}}{12\left(1-v_{x} v_{\theta}\right)}
\end{aligned}
$$

in simpler form:

$$
\left\{\sigma_{m}\right\}=[D]\left[B_{m}\right]\left\{\delta_{m}\right\}
$$




\section{Stiffness and Force Matrices}

The total potential energy of a conical shell strip subjected to a load q can be expressed as [7, 9]:

$$
\begin{aligned}
& U_{t}=\frac{1}{2} \int_{A}\{\varepsilon\}^{T}\{\sigma\} d A-\int_{A q} q\{\delta\}^{T} d A \\
& =\frac{1}{2} \sum_{n=1}^{\infty} \sum_{m=1}^{\infty}\left\{\delta_{m}\right\}^{T} \int_{0}^{r^{r}} \int_{r_{i}}\left[B_{n}\right]^{T}[D]\left[B_{m}\right]\left\{\delta_{m}\right\} r d r d \theta-\sum_{m=1}^{\infty} \int_{A q} q\left\{\delta_{m}\right\}^{T}[C] r d r d \theta
\end{aligned}
$$

Due to the orthogonality of the displacement functions, when $m=n$ the double products vanish and for $\mathrm{m} \neq \mathrm{n}$ the equation becomes:

$\int_{0}^{a} \sin ^{2} \frac{m \pi \theta}{\alpha} d \theta=\int_{0}^{a} \cos ^{2} \frac{m \pi \theta}{\alpha} d \theta=\frac{\alpha}{2}$

substituting Eq. (20) into (19) and minimizing the resulting expression with respect to all of deformation amplitudes leads to:

$$
\sum_{m=1}^{n} \frac{\alpha}{2} \int_{r_{i}}^{r_{j}}\left[B_{n}\right]^{T}[D]\left[B_{m}\right] r d r=\sum_{m=1}^{n} \int_{A q} q[C] r d r d \theta
$$

The strip stiffness matrix of size $(15 * 15)$, for a typical harmonic $\mathrm{m}$ follows from Eq. (21) can be expresses as :

$$
[K]=\frac{\alpha}{2} \int_{r_{i}}^{r_{j}}\left[B_{m}\right]^{T}[D]\left[B_{m}\right] r d r
$$

The strip force vector of size $(15 * 1)$, for a typical harmonic m follows from Eq. (21) as:

$$
\{F\}=\int_{A q} q[C] r d r d \theta
$$

Before assembling the strip stiffness matrix to form the structure stiffness, Eq. (22) has to be transformed in to global coordinates.

$$
\left.\left[K^{-}\right]=[T][K] T\right]^{T}
$$

in which $[\mathrm{T}]$ is the transformation matrix and $\left[K^{-}\right\rfloor$is the global stiffness matrix

\section{Modeling of the vehicle and bridges}

The use of curved bridges in interchanges of modern highway systems is popular because of increased demand for curved roadway alignments for the smooth passage of congested traffic and modern emphasis on aesthetic considerations. Box girders are the most preferred section for curved bridges on account of their high torsional capacity [10].

The vehicle is idealized as a single moving force by neglected the dynamic interaction between the vehicle and bridge, also the vehicle is idealized as a moving mass consist of (sprung mass- damped-spring) with dynamic interaction is considered. 


\section{Equations of the dynamic response}

The forced vibration equation defining motion may be expressed as $[11,12,13]$ :

$\left[M_{c}\right]\left\{\ddot{\delta}_{m}\right\}+\left[C_{b}\right]\left\{\dot{\delta}_{m}\right\}+\lfloor K\rfloor\left\{\delta_{m}\right\}=\{F\}$

In which $\left\{\delta_{m}\right\}$ represent the nodal global degree of freedom including both bending and in-plane effects $\left[M_{c}\right],\left[C_{b}\right]$ and $[K]$ are the mass, damping and stiffness matrix of structure, respectively, $\left\{\ddot{\delta}_{m}\right\}$ and $\left\{\dot{\delta}_{m}\right\}$ are the acceleration and velocity amplitude vectors respectively. The load vector $\{F\}$ represent the nodal loads caused by presence of vehicles upon the deck, which varies as the vehicle traverses across the bridge.

\section{Solution of the equation of motion}

Equation (25) represents the matrix differential equation of system motion. Let $\left\{\Delta \delta_{m}\right\}$ denote the increment in $\left\{\delta_{m}\right\}$ occurring during the time step from(t to $\left.\mathrm{t}+\Delta \mathrm{t}\right)$. By New marks finite difference scheme, the vector $\left\{\delta_{m}\right\}$ and its derivatives at the instant $(\mathrm{t}+\Delta \mathrm{t})$ can be related to those at the instant [14].

$$
\begin{aligned}
& \left\{\ddot{\delta}_{m}\right\}_{t+\Delta t}=a_{0}\left\{\Delta \delta_{m}\right\}-a_{2}\left\{\dot{\delta}_{m}\right\}_{t}-a_{3}\left\{\ddot{\delta}_{m}\right\}_{t} \\
& \left\{\dot{\delta}_{m}\right\}_{t+\Delta t}=\left\{\dot{\delta}_{m}\right\}_{t}+a_{6}\left\{\ddot{\delta}_{m}\right\}_{t}+a_{7}\left\{\ddot{\delta}_{m}\right\}_{t+\Delta t} \\
& \left\{\delta_{m}\right\}_{t+\Delta t}=\left\{\delta_{m}\right\}_{t}+\left\{\Delta \delta_{m}\right\}
\end{aligned}
$$

where the quantities with subscript $t$ are those occurring at time $t$, assumed to be known. Using New mark's parameters $\beta$ and $\gamma$, the coefficient and those to be used later can be given

as:

$$
a_{0}=\frac{1}{\beta \Delta t^{2}}, a_{1}=\frac{\gamma}{\beta \Delta t}, a_{2}=\frac{1}{\beta \Delta t}, a_{3}=\frac{1}{2 \beta}-1, a_{4}=\frac{\gamma}{\beta}-1,
$$

$$
a_{5}=\frac{\Delta t}{2}\left(\frac{\gamma}{\beta}-2\right), a_{6}=\Delta t(1-\gamma), a_{7}=\gamma \Delta t
$$

The parametric value of $\beta=0.25$ and $\gamma=0.5$ are used throughout, implying that the marching scheme is unconditionally stable. After calculate the initial acceleration vector $\left\{\ddot{\delta}_{m}\right\}_{0}$ at time $\mathrm{t}=0$.

$$
\left\{\ddot{\delta}_{m}\right\}_{0}=\left[M_{c}\right]^{-1}\left(\left\{F_{(0)}\right\}-\left[C_{b}\right]\left\{\dot{\delta}_{m}\right\}-[K]\left\{\delta_{m}\right\}\right)
$$

And forming the effective stiffness matrix $[K]^{*}$ :

$$
[K]^{*}=[K]+a_{0}\left[M_{c}\right]+a_{1}\left[C_{b}\right]
$$

It will be possible, for each time step, to calculate the dynamic response in the following steps:

1.calculate the effective force vector at time $\mathrm{t}+\Delta \mathrm{t}$ as following

$$
\begin{aligned}
& \{F\}^{*}{ }_{t+\Delta t}=\{F\}_{t+\Delta t}+\left[M_{c}\right]\left(a_{0}\left\{\delta_{m}\right\}_{t}+a_{2}\left\{\dot{\delta}_{m}\right\}_{t}+a_{3}\left\{\ddot{\delta}_{m}\right\}_{t}\right)+ \\
& {\left[C_{b}\right]\left(a_{1}\left\{\delta_{m}\right\}+a_{4}\left\{\dot{\delta}_{m}\right\}_{t}+a_{5}\left\{\ddot{\delta}_{m}\right\}_{t}\right)}
\end{aligned}
$$

2. solve for the displacement at time $\mathrm{t}+\Delta \mathrm{t}$ :

$$
[K]^{*}\left\{\delta_{m}\right\}_{t+\Delta t}=\{F\}^{*} t+\Delta t
$$




$$
\left\{\delta_{m}\right\}_{t+\Delta t}=[K]^{*-1}\{F\}^{*} t+\Delta t
$$

Equation (34) sometimes called the pseudo-static equation.

3. calculate the correct value of acceleration and velocities for contact point at time $t+\Delta t$ :

$$
\begin{aligned}
& \left\{\ddot{\delta}_{m}^{c p}\right\}_{t+\Delta t}=\left\{\ddot{\delta}_{m}^{c p}\right\}_{t}+a_{0}\left\{\Delta \delta_{m}^{c p}\right\}_{t}-a_{2}\left\{\dot{\delta}_{m}^{c p}\right\}_{t}-a_{3}\left\{\ddot{\delta}_{m}^{c p}\right\}_{t+\Delta t} \\
& \left\{\dot{\delta}_{m}{ }^{c p}\right\}_{t+\Delta t}=\left\{\dot{\delta}_{m}{ }^{c p}\right\}_{t}+a_{6}\left\{\ddot{\delta}_{m}{ }^{c p}\right\}_{t}+a_{7}\left\{\ddot{\delta}_{m}{ }^{c p}\right\}_{t+\Delta t}
\end{aligned}
$$

The equation of motion for sprung mass express by the following matrix $[13,15,16]$.

$\left[m_{v}\right]\left\{\ddot{\delta}_{v}\right\}+\left[C_{v}\right]\left\{\dot{\delta}_{v}\right\}+\left[K_{v}\right]\left\{\delta_{v}\right\}=\left\{f_{v}\right\}$

Calculate the effective force for sprung mass at time $\mathrm{t}+\Delta \mathrm{t}$ as following:

$$
\begin{aligned}
& \left\{\ddot{\delta}_{v}\right\}_{t+\Delta t}=\left[m_{v}\right]^{*-1}\left\{f_{v}\right\}^{*} \\
& {\left[m_{v}\right]^{*}=\left[m_{v}\right]+a_{0}\left[K_{v}\right]+a_{1}\left[C_{v}\right]} \\
& \left\{f_{v}\right\}^{*}=\left\{f_{v}\right\}_{t+\Delta t}-\left[C_{v}\right]\left\{\dot{\delta}_{v}\right\}_{t+\Delta t}-\left[K_{v}\right]\left\{\delta_{v}\right\}_{t+\Delta t}
\end{aligned}
$$

Finally to calculate the response of bridge at time $t+\Delta t$ for sprung mass according to:

$$
\begin{aligned}
& \left\{\delta_{v}\right\}_{t+\Delta t}=(\Delta t)^{2} \beta\left\{\ddot{\delta}_{v}\right\}_{t+\Delta t}+\left\{\delta_{v}\right\}_{t}+\Delta t\left\{\dot{\delta}_{v}\right\}_{t}+1 / 2(\Delta t)^{2}(1-2 \beta)\left\{\ddot{\delta}_{v}\right\}_{t+\Delta t} \\
& \left\{\dot{\delta}_{v}\right\}_{t+\Delta t}=\Delta t \gamma\left\{\ddot{\delta}_{v}\right\}_{t+\Delta t}+\left\{\dot{\delta}_{v}\right\}_{t}+\Delta t(1-\gamma)\left\{\ddot{\delta}_{v}\right\}_{t+\Delta t}
\end{aligned}
$$

\section{Numerical Example:}

Dynamic analysis of curved box-girder bridges with two cell (Bridge-1).

The model, which was tested in ref.[17], was a two cell curved box girder bridge under $(345 \mathrm{kN})$ moving force, the cross section dimensions are shown in Fig. (1) and the following data: Young's modulus $\left(\mathrm{E}=2.11 \times 10^{10} \mathrm{~N} / \mathrm{m}^{2}\right.$ ), Poisson Ratio(0.3), Mass Density $\left(\rho=2400 \mathrm{~N} / \mathrm{m}^{3}\right)$, Radius $(\mathrm{R}=305 \mathrm{~m})$, Angle $(\alpha=0.1 \mathrm{rad})$.

The transverse section is discredited using (11) higher order finite strips as shown in Fig. (2), the speed of vehicle is $(110 \mathrm{~km} / \mathrm{hr})$ along the longitudinal centerline of the bridge. Figs. (3 and 4) show the mid-span static and dynamic deflection of the outer edge of the deck at $(\mathrm{R}=309 \mathrm{~m})$. Figs. (5 and 6) show the med-span static and dynamic deflection at center line of bridge.

The dynamic increment factor (Imp.), for the center line of bridge is given in Fig(7)., results are in good agreement with the values obtained by the finite element method [17].

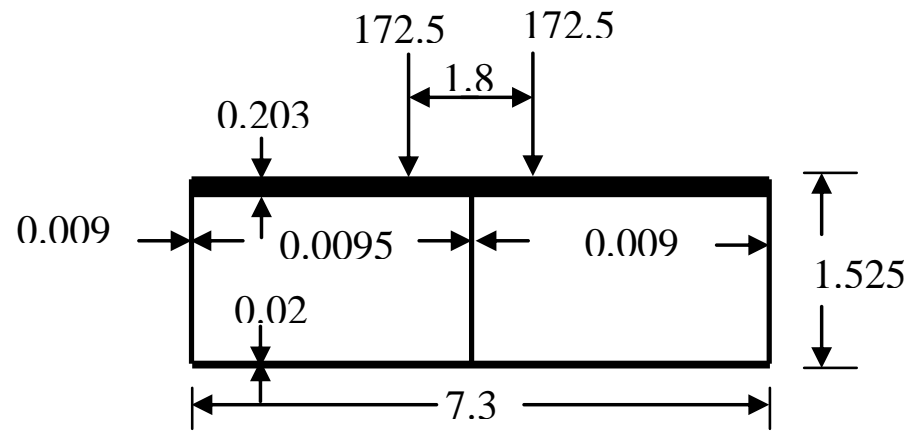

Fig. (1) Cross section of (Bridge- 1).

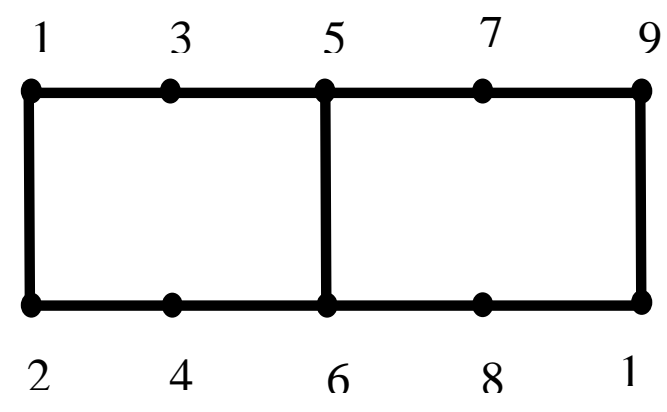

Fig. (2) Box girder (Bridge-1) divided by finite strips. 
Abdul- Razzak: Dynamic Analysis of Curved Box Girder Bridges

$\theta / \alpha$

$\theta / \alpha$

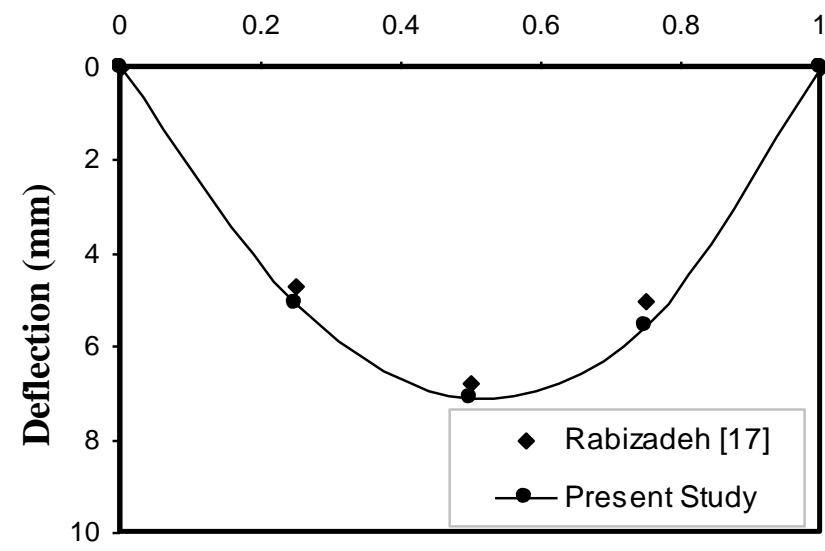

Fig. (3) Mid-span static deflection at outer edge of (Bridge-1) $\theta / \alpha$

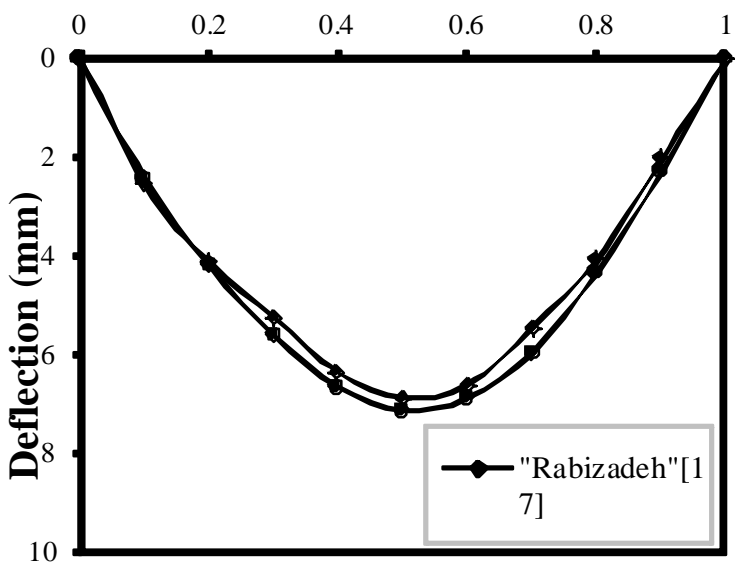

Fig. (5) Mid-span static deflection at center line of (Bridge-1)

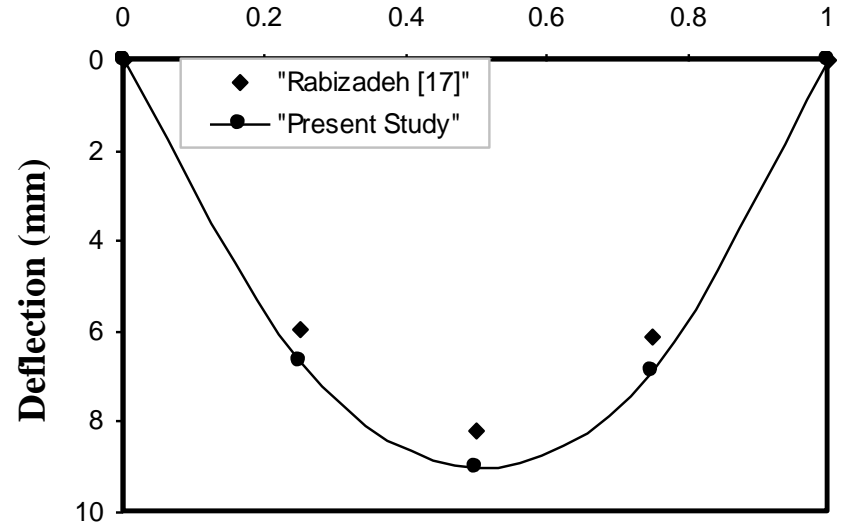

Fig. (4) Mid-span dynamic deflection at outer edge of (Bridge-1)

$\theta / \alpha$

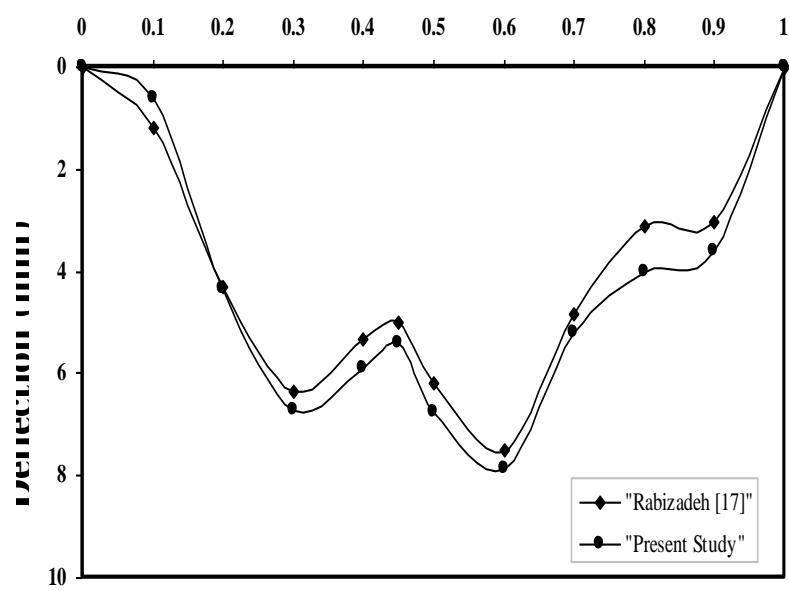

Fig. (6) Mid-span dynamic deflection at center line of

(Bridge-1)

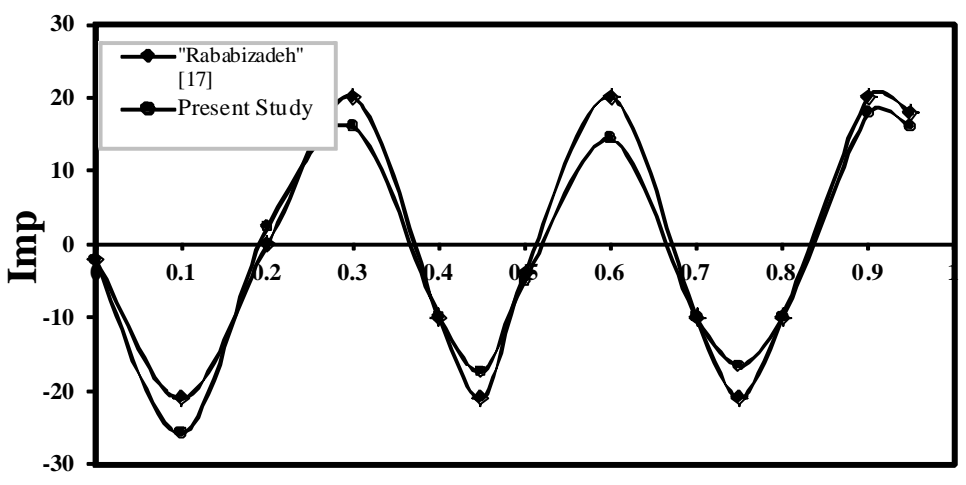

Fig. (7) Dynamic Impact Factor at center line of (Bridge-1) 


\section{Conclusions:}

Sixth order finite strip and third order in plane strip with auxiliary nodal line are used successfully for the solution of curved box-girder bridges under dynamic response.

The normalized displacement increased by increasing the distance of the moving force on the bridge until it reach a center of space after that is begin by decreasing.

Comparison of the results shows that an increase in the dynamic deflcetion compared to static deflection. The dynamic deflection is approximately $(26.5 \%)$ greater than the maximum static deflection.

Accurate results are found using the higher order finite strip method when compared the finite element solution.

\section{References}

[1] Humar, J.L. and Kashif, A.M., "Dynamic Response of Bridges under Travelling Loads”, Canadian Journal of Civil Engineering, Vol.20, 1993, pp.287-298.

[2] Mukherjee, D. and Trikha, D.N., "Behaviour of Curved Concrete Box Girder under Dynamic Loading”, Proceeding Institution Civil Engineers., Part.2, Vol.69, Jun, 1980, pp. 543-553.

[3] Senthilvasan, J., Brameld, G.H. and Thambiratnam, D.P., "Bridge-Vehicle Interaction in Curved Box Girder Bridges”, Micro Computers in Civil Engineering, Vol.12, 1997, pp.171-181

[4] Abdul-Razzak, A.A., and Mohammad, A.A., "Dynamic Analysis of Box Girder Bridges Using Higher Order Finite Strip Method”, AL-Rafidain Engineering Journal, Vol.10, No.1, 2005.

[5] Abdul-Razzak, A.A., and Haido J.H., "Forced Vibration Analysis of Rectangular Plates Using Higher Order Finite Layer Method”, AL-Rafidain Engineering Journal, AL-Rafidain Engineering Journal, Vol.16, No.5, 2008.

[6] Abdul-Razzak, A.A., and Haido J.H., "Numerical Simulation of Interaction Between Slab-Type Bridges and Moving Vehicles", International Conference on Innovative and Smart Structural Systems for Sustainable Habitat, 3-5 ${ }^{\text {th }}$ Jan. 2008.

[7] Abdul-Razzak, A.A, "Finite Strip Analysis of Curved Box Girder", AL-Rafidain Engineering Journal, Vol.2, No.2, 1994, pp.122-142

[8] Novozhilov, V.V., "Theory of Thin Shells", Second Edition, Groningen, P. Noordhoff, 1964.

[9] Abdul-Razzak, A.A. and Najem, R.M., "Solution of Curved Box Girder Bridges with Intermediate Diaphragms”, AL-Rafidain Engineering Journal, Vol.10, No.1, 2002, pp.1-22.

[10] Senthilvasan, J., Thambiratnam, D.P. and Brameld, G.H., "Dynamic Response of $A$ Curved Bridge under Moving Truck Load”, Engineering Structures, Vol.24, No.10, 2002, pp.1283-1293.

AL- Niemi , "Dynamic Analysis of Curved Box Girder Bridges Using Higher Order

[11] Finite Strip", M.Sc. Thesis, University of Mosul, Civil Engineering Dept., 2006.

[12] Weare, W. and Johnston, P.R., "Structural Dynamic By Finite Element”, Prentic-Hall International, New Jersey, 1985.

[13] Kwon, H.C., Kim, M.C. and Lee, I.W., "Vibration Control of Bridges Under Moving Loads”, Computers and Structures, Vol.66, No.4, 1998, pp.473-480.

[14] Yang, Y.B. and Yau, J.D., "Vehicle Bridge Interaction Element for Dynamic Analysis”, Journal of Structural Engineering, Vol.123, No.11, Nov. 1997, pp.1512- 
1518.

[15] Mermertas, V., "Dynamic Interaction Between The Vehicle and Simply Supported Curved Bridge Deck”, Comput. Methods Appl. Mech. Engrg., Vol.162, 1998, pp. 125-131.

[16] Hawk, H. and Ghali, A., "Dynamic Response of Bridge to Multiple Track Loading”, Canadian Journal of Civil Engineering, Vol.8, 1981, pp.392-401.

[17] Rabizadeh, R.O. and Shore, S., "Dynamic Analysis of Curved Box Girder Bridges", Journal of The Structural Division, Proceeding of ASCE, Vol.101, No.ST9, Sep., 1975, pp.1899-1912. 